\title{
Feasibility Analysis on the Application of "Flipped Class" Teaching Mode to Music Teaching in Colleges and Universities
}

\author{
Hao Xin \\ College of Music, Baicheng Normal University, Baicheng, China \\ 348529918@qq.com
}

Keywords: Flipped Class, Teaching Mode, Music Teaching, Feasibility

\begin{abstract}
With the continuous improvement of people's living standards, the education has also ushered in a huge change. As a new teaching mode, "flipped class" has more and more widely used in music teaching in colleges and universities. In recent years, the teaching mode has made great innovations in teaching method, teaching content, role playing of teachers and students, and has broken the impression of traditional music teaching mode. Music education in colleges and universities has its own particularity, and pays great attention to practical teaching. Considering the differences of students' musical foundation and their learning ability, the "flipped class" teaching mode has become a good way for music teaching in colleges and universities. This paper will analyze the current situation of the application of the "flip classroom" teaching mode, and study the feasibility of its application to the music teaching in colleges and universities. Finally, the author will make the corresponding countermeasure analysis to the application of this model to provide the reference material for the university music education.
\end{abstract}

\section{Introduction}

As a new teaching mode, "flipped class", also called "inverted classroom", completely breaks the shackles of traditional "classroom knowledge imparting" and "the internalization of knowledge under class", the order of the two is reversed and the online learning method is used to allow students to choose their learning resources according to their own learning progress, so that the students can master the corresponding learning speed. In this mode, the teaching of knowledge is finished before class. What we need to do in class is learning activities, through the guidance of teachers to enable students to internalize their knowledge in the classroom. The traditional music education mode is often spoon-fed teaching, which results in students losing their learning initiative, the teaching process will become rigid, the overall teaching effect will not be satisfactory, and the "flipped class" will change the traditional teacher-student relationship and has brought innovation to the teaching context, and the teaching effect is more obvious. However, in the process of applying this model to the music education in colleges and universities, it is necessary to consider the technical and practical nature of the subject and constantly innovate to promote its application and development in practical teaching.

\section{The Present Situation of the Application of the Teaching Mode of "Flipped Class"}

Flipped class first appeared at a primary school in Rocky Mountain, Colorado, where two teachers initially had to make up classes for absent students. The method used is to spread the knowledge of the course to the Internet through the PPT medium. However, it was later found that it was not enough to spread the knowledge with the PPT alone, and the students' questions could not be answered in time. Therefore, teachers begin to play PPT and video in class again, students can solve all kinds of questions in the process of watching PPT and video, and the teaching efficiency has been improved obviously. After a long period of application, this teaching model has been well received by other teachers and students, not only in primary schools, but also in secondary schools and colleges and universities at all levels. With the popularization of Internet technology, this kind 
of teaching model has been recognized one after another [1]. Flipped teaching has attracted more attention, especially as the spread of social networking sites has made the world more aware of it.

In the early stage of "flipped class" teaching mode applied to music education in colleges and universities in our country, it is usually through the use of courseware to carry out teaching practice, students can also use courseware to review what they have learned. Since the main purpose of music teaching in colleges and universities is to instruct students to carry out practical operations in the classroom, and then to consolidate the music knowledge learned on that day through hands-on operations, that has transformed the traditional learning mode of "teaching, reviewing and homework" into "preview". With the continuous development of Internet technology in recent years, the "flipped class" teaching mode has gradually begun to develop on the network platform. For example, some colleges and universities in our country have set up "network flipped class" in music teaching, so that teachers and students can interact and communicate in this network classroom, thus improving the whole teaching efficiency and teaching quality, and the students' learning effect will be improved constantly.

\section{The Feasibility of "Flipped Class" Teaching Model Applied to Music Teaching in Colleges and Universities}

The music teaching mode of most universities in China is similar, and the method of collective teaching is often adopted. With the popularization of digitalization and the continuous progress of science and technology, the "flipped class" teaching mode also occupies a place in the music education of colleges and universities. The teaching of music is quite different from the teaching attributes of Chinese and mathematics, and music is an art that needs to be adapted to vision and hearing. The dissemination of music knowledge also needs to take into account the visual and listening aspects to ensure the quality of teaching. The application of the "flipped class" teaching mode is not only to meet the development of the times, but also to meet the needs of the spread of subject art.

\subsection{The Characteristics of the Teaching Mode of "Flipped Class".}

The application of "flipped class" teaching mode in music education in colleges and universities is usually based on certain steps, which ensures the effect of flipping teaching. First of all, in the preparation of teaching content, teachers pay attention to determine the direction and central theme of classroom teaching, highlight the key points of teaching, and under the flipped mode, teachers will enrich the teaching content by using streamlined video or PowerPoint courseware in the classroom. Dissemination of professional knowledge, through the classroom itself knowledge reserves and related materials to find to integrate and refine the knowledge points, so that the entire classroom becomes logical, rigorous thinking; Secondly, in the teaching content display means, the technical level each teacher usually will use each kind of information equipment, commonly has the projector, the computer, the television and so on, the data production level teacher often will use each kind of humorous element, the social hot spot, new jokes to attract students' attention, stimulate students' enthusiasm for learning[2]; Finally, in terms of teacher-student interaction in the classroom, that is, when the teacher plays videos and slides, it is essential to ask questions in the classroom, so that everyone can participate actively through the relevant questions, which can also increase the students' sense of existence and self-confidence. Allowing students to learn in interaction can also effectively improve their learning efficiency.

In the process of implementing music education in colleges and universities, we should pay attention to several problems. One is the control of initiative. In traditional music teaching, teachers are all responsible for grasping the initiative of the whole classroom, which determines the direction of teaching and the progress of teaching. In order to apply the mode of "flipped teaching" well, the initiative should be transferred to the students, and the students should grasp the classroom themselves, and the teachers should also change from the classroom leaders to the teaching guides. Second is to grasp the information technology and digital technology, teachers themselves need to have a certain degree of information and digital literacy, to master a certain amount of information 
technology to ensure the smooth production of various digital courseware and display video. Considering that the students are also part of the classroom, the students in the "flipped class" should also have some understanding of various information and digital technologies; the study of the students' learning state is three. The "flipped class" mode emphasizes the active participation of the students in class and under the class. It is a very important step for the students to use the courseware of teachers or to preview the video data. In this way, the students can find the difficult points in their study process before class and thus in the course of class. The teacher will solve it again, and for the students' learning state, it is required that every student can learn actively, actively cooperate with each teaching step and participate in every teaching link.

\subsection{The Advantages of the "Flipped Class" Teaching Model.}

The advantages of "flipped class" teaching mode applied to music education in colleges and universities are mainly reflected in four aspects. The first one is that the teaching contents are more innovative. In the traditional teaching mode, music teaching is carried out through music playing or the introduction of music theory knowledge on books, which is slightly dull. "Turning the classroom" makes the teaching content innovative, adding video and pictures to make the whole classroom lively and lively, the content of the teaching becomes easy to accept. The second aspect is the change of students status. In traditional music teaching, teachers occupy the main position of the classroom, students are in a passive state. In the music teaching under the "flipped class", the students lead the classroom to the direction of various music activities. Artistic communication is carried out independently, which greatly improves the students initiative in learning and their abilities in all aspects. The third aspect is the increase of interaction between teachers and students, and the "flipped class" has created a great space for students to give full play, especially in the process of students' preparation, they need the students to cooperate with each other in order to solve the problems that arise in the process of self-study. In class, students need to take the initiative to put forward their own difficulties to solve by everyone, asking for help from the teacher is also one of the ways to solve the problem, and it also increases the interaction between teachers and students. The fourth aspect is the realization of teaching liberalization. "Flipped teaching" makes use of the internet and multimedia, and students in colleges and universities can preview the relevant music theory knowledge and culture in their dormitories in advance through the internet, which realizes the liberalization of teaching scenes. Students in the class by looking for information to complete their study or through the internet to solve their own difficult problems is the realization of learning liberalization [3].

\section{Suggestions on the Application of the Teaching Mode of "Flipped Class" to the Music Teaching in Colleges and Universities}

\subsection{Doing Well the Pre-Class Analysis of Music Teaching in Colleges and Universities.}

The pre-class design of music teaching in colleges and universities under the mode of "flipped class" is very necessary, among which the most important problem is the production of video resources, which should not only include the music knowledge to be disseminated. It is also possible to design the problems that need to be considered before class. In the actual application process, the classroom needs to examine the actual situation of the students, including the degree of knowledge, the ability to learn, and then according to the contents of the curriculum and the characteristics of the students. For example, when explaining notes and stops, the teacher can use video to teach music, which can not only deepen the students' impression, but also improve the students' understanding ability; For example, when a teacher explains the difference between two and all, it can be analyzed in detail in the form of a slide in the slide. The teachers should inform the students of the contents to be explained before class, so that students can make preparations according to the existing video resources and courseware and find out the related problems so that they can deal with these problems in the classroom in a unified way [4]. 


\subsection{Starting with Details to grasp the Key Points of Music Teaching in Colleges and Universities.}

When the "flipped class" teaching mode is applied to music education in colleges and universities, the commonly used resources include slides, small videos, animated pictures and so on. How to make students grasp the music knowledge that teachers want to spread in the limited time classroom is a problem worth studying. The first detail that should be paid attention to is that the teacher should start with the details, grasp the main contents of the class, make videos and slides around the classroom central problem, and pay attention to the use of interesting expressions. In the process of spreading art and culture, students can enjoy the fun of the classroom. For example, when appreciating some music works, teachers should analyze the changes of rhythm and melody in the whole music. The different characteristics of the musical instruments and various musical instruments should also be understood by the students. Secondly, in the process of preparing video resources or slides, the teachers should pay attention to the core content of each section of the music class, to refine the various knowledge points, grasp all kinds of neglected details, so that the entire video and slide become more rigorous and more logical [5].

\subsection{Innovating the Music Classroom Activities in Colleges and Universities and Enlivening the Classroom Atmosphere.}

The "flipped class" teaching mode pays attention to the students' main position and needs the students to control the whole classroom autonomously. Therefore, it is necessary to innovate a large number of classroom activities to enable the students to actively participate in the classroom atmosphere and to enliven the classroom atmosphere together. The music classroom itself is a classroom full of joy and artistic atmosphere, we can use class discussion activities to focus on the problems encountered by students in the process of learning music by way of grouping. Through the form of group discussion to stimulate the students' interest in learning, we can also carry out a question-and-answer activity with prizes to display all kinds of problems, encourage students to find information to solve the problems, and make full use of all kinds of teaching resources and give play to the main role of the students in the classroom [6].

\subsection{Establishing Feedback Mechanism after Music Teaching in Colleges and Universities.}

The music teaching in the "flipping classroom" mode also pays attention to the interaction between teachers and students after class, which requires teachers and students to share their classroom feelings and learning experiences with each other after class, so that students can evaluate the teaching content of teachers and put forward the corresponding suggestion to optimize the classroom teaching; Teachers can analyze the students' learning situation, solve the problems encountered in their study, and help students understand themselves. The so-called "to teach is to learn" means that both students and teachers can make progress in the teaching process, and the "flipped class" model exercises teachers' teaching ability and students' ability to learn independently, and the establishment of after-class feedback mechanism will promote the improvement of both abilities, thus enhancing classroom quality and improving teaching efficiency.

\section{Conclusion}

The application of "flipped class" teaching mode in the music classroom of colleges and universities opens up a new direction for the reform of the music curriculum, which subverts the traditional music teaching mode, innovates the teaching contents of the music classroom, changes the classroom status of the teachers and students, increases the interactive communication between teachers and students, realizes the teaching liberalization, and greatly improves the classroom quality and the student learning efficiency. Taking into account the flexible and changeable teaching strategy of "flipped class", teachers should improve their literacy in all aspects, accumulate various teaching experiences in the new era, and students should also give full play to their initiative and participate in various classroom activities to inspire musical inspiration and improve artistic 
literacy.

\section{References}

[1] He Yuhang. Study on the characteristics and challenges of the application of the "flipped class" model in the music teaching in colleges and universities [J]. Art Evaluation, 2018(09):84-85.

[2] Yu Haiping. Discussion on the application of the "flipped class" model in the music teaching in colleges and universities [J]. Journal of Jiamusi Vocational Institute, 2017(05):184-185.

[3] Xiao Yuanyuan. Study on the "flipped" Mode in the music classroom of colleges and universities [J]. Music Time and Space, 2015(23):124-125.

[4] Kang Xiaodan. Exploration on the construction of music flipping classroom model in colleges and universities [J]. The Science Education Article Collects, 2016(07):78-79.

[5] Wang Wenxia. An analysis of the application of "flipped class" model in music teaching in colleges and universities [J]. Art Evaluation, 2017(08):127-128.

[6] Cao Xiaojing. Feasibility analysis on the application of "flipped class" teaching mode to music teaching in colleges and universities [J]. Art Education, 2016(03):68-69. 